\section{P125 RECURRENT KAWASAKI DISAESE IN CHILDHOOD}

Sabina Khalilova*. Modern Hospital, Baku, Azerbaijan

10.1136/archdischild-2019-epa.480

Introduction Kawasaki disease is a multisystemic disease characterized by high fever,skin rash,cervical lymphadenopathy , mucosal changes,swelling of the hands and feet and occurs mainly under 5 years of age.First observed in Japan 1967 by doctor Tomisaku Kawasaki .Reccurence is a rare phenomenon and occurs most commonly in children $3 \%$ of all patients diagnosed with Kawasaki disease.Reccurence of the disease is even less frequent and is more likely to be atipical or incomplete. We describe child who had recurrent Kawasaki disease and recovered with intravenous immunoglobulin (IVIG)

Material and method in 2017 October 3 years old girl was presented 7 day history of high fever,sore throat,neck swelling,nonpurulant conjunctivitis, cracked lips ,strawberry tongue.An eritematous maculopapular rash was observed on the trunk.Laboratory evaluation revealed hemoglobin 10,2 g/ $\mathrm{dL}$, white blood cell $18,200 \mathrm{cell} / \mathrm{mm}^{3}$, C-reactive protein 250 $\mathrm{mg} / \mathrm{L}$,platelet count $230,000 \mathrm{cell} / \mathrm{mm}^{3}$, erithrosyte sedimentation rate $56 \mathrm{~mm} / \mathrm{h}$, asparate aminotransferase $52 \mathrm{U} / \mathrm{L}$, alaninamintransferase 23.ECHO revealed ecstatic mid and distal left $(3,5 \mathrm{~mm})$ coronary artery.Liver and renal function tests, urinalysis, urin culture test,blood culture test were negative or normal.Chest X-ray and abdominal USG were normal.Tests for Epstein -Barr virus, cytomegalovirus were negative. We started Intravenous immunoglobulin $2 \mathrm{gr} / \mathrm{kq} /$ day and oral aspirin $100 \mathrm{mg} / \mathrm{kg} /$ day .During 6 hours her symptoms was resolved.Fever resolved and conjunctivitis regressed within the first hours, where as rush $\mathrm{w}$ and edema disappeared gradually within 6 hours.Desquamation of the fingertips occurred on the 12 th days of the illness.Aspirin was reduced an antiaggregant dose within 8 week $(5 \mathrm{mg} / \mathrm{kg})$ But after 1 month she had high fever again and we started IVIG $2 \mathrm{~g} / \mathrm{kg} /$ 12 h. Duration of fever was short, she had not typical findings at the recurrence and and had a good response to the first dose of IVIG.

Result In this case we present patient who had recurrent Kawasaki disease with no complications Follow-up echocardiogram after 2 months and 8 months showed no complications Conclusion In our case we described patient who had recurrent Kawasaki disease and treating at the time we could prevent complications.

\section{P126 TRANSLATING THE SCIENCE OF EARLY CHILDHOOD DEVELOPMENT INTO PRACTICE, TO SUPPORT VULNERABLE FAMILIES AND CHILDREN IN A LOW- INCOME IRISH COMMUNITY}

${ }^{1}$ Margaret Curtin*, ${ }^{2}$ Lynn Buckley. 'University College Cork, Cork, Ireland; ${ }^{2}$ Young Knocknaheeny Area-based childhood programme, Cork, Ireland

10.1136/archdischild-2019-epa.481

Intergenerational poverty in established low-income communities has significant negative consequences for child health and development. The psychological and neurodevelopmental mechanisms through which adverse childhood experiences (ACEs) impact on the developing brain are well understood. What is not yet understood is how to translate this science into effective frameworks for good practice in supporting families and children facing intergenerational adversity.

Young Knocknaheeny (YK) is an interagency collaboration aiming to reduce child poverty and enhance child development (age 0 to 6) through a whole community prevention and early intervention approach. The programme is underpinned by an innovative Infant Mental Health (IMH) framework and draws on international best-practice in evidencebased approaches.

YK works through a relationship based model, primarily supporting the development of quality skills and environments using coaching, modelling, mentoring and continuous professional development of practitioners working with children and families. YK also provides direct support to families through a progressive universal to targeted IMH service model.

A process evaluation of the programme was undertaken between 2015 and 2017 for the explicit purpose of examining the nuanced processes required for translating the science (and international best practice) to respond to local contextual needs and priorities.

Aim The overall aim was to evaluate the processes and approach to implementing the YK programme and identify enablers and barriers to effective adaptation of evidence-based practice.

Methods The Centre for Disease Control (CDC) Framework for Programme Evaluation in Public Health was utilised to imbed practical, ongoing evaluation strategies within the programme. A mixed-methods approach was adopted. Administrative programme data were analysed to assess reach and determine levels of engagement. Qualitative methods were used to understand the implementation processes. Early Childhood Environment Rating Scale (ECERS) was used to assess childcare quality.

Results Stakeholders, practitioners and parents report positive experiences of engaging with the YK programme. The IMH framework provided a common language for practitioners, a mechanism for inter-disciplinary working and an effective support for engaging vulnerable families. This in turn resulted in improved inter-agency working and greater co-ordination and planning around family's/children's needs. An adapted mentoring, coaching and quality improvement programme resulted in very significant improvements in childcare quality.

Conclusion Tailored programmes of targeted and universal interventions to support early childhood development can mitigate the effects for children and families. A number of evidence-based approaches may be utilised. However, local contextual complexity must be addressed if the most vulnerable families are to be included.

\section{P127 OROFACIAL CLEFTS AND OCULAR ANOMALIES: A 27 YEAR REVIEW OF A PORTUGUESE TERTIARY HOSPITAL}

${ }^{1}$ Tiago Magalhães*, ${ }^{1}$ Ana Rita Curval, ${ }^{1}$ Rita Pissarra, ${ }^{1}$ Vanessa Gorito, ${ }^{2}$ Augusto Magalhães, ${ }^{3}$ Ana Maia. ${ }^{1}$ Centro Materno Pediátrico - Centro Hospitalar São João, Porto, Portugal; ${ }^{2}$ Ophthalmology Department - Centro Hospitalar São João, Porto, Portugal; ${ }^{3}$ Transdisciplinary Group for Cleft Lip and Palate - Centro Hospitalar São João, Porto, Portugal

\subsection{6/archdischild-2019-epa.482}

Introduction/aim Orofacial clefts (OFC) are the most common congenital malformation worldwide with an estimated prevalence of 1.55 per 1000 live births in Europe. The etiology of OFC is thought to be multifactorial with genetic and 